\title{
Failed bioprosthetic valve approaches: Transcatheter aortic valve replacement approach
}

\author{
Aaron Clark, MD, and S. Chris Malaisrie, MD
}

Bioprosthetic valves will fail, given enough time. All prosthetic valves, whether mechanical or biological, are beset with nonstructural valve deterioration due to such causes as infective endocarditis and pannus formation, but bioprosthetic valves are uniquely prone to structural valve deterioration (SVD) caused by calcification or wear, leading to either stenosis or regurgitation (Figure 1, $A$ and $B$ ). ${ }^{1}$ The combination of SVD and non-SVD constitutes what is now termed bioprosthetic valve failure (BVF). ${ }^{2}$ A transcatheter approach to SVD using the valve-in-valve (VIV) procedure is now well accepted for the treatment of SVD. But should aortic VIV be the preferred procedure for most patients?

\section{TREATMENT OPTIONS FOR BIOPROSTHETIC VALVE FAILURE}

Reoperative cardiac surgery with repeat aortic valve replacement (AVR) was once the only therapeutic option for BVF, but the operative risk of reoperative AVR is not negligible. Over the last 2 decades, reported 30-day mortality for reoperative AVR ranged from $3.5 \%$ to $8.4 \% .^{3-5}$ Moreover, the morbidity of the operation included stroke $(1.2 \%)$, renal failure $(5.6 \%)$, prolonged intubation $(16.7 \%)$, reoperation for bleeding $(5.6 \%)$, and deep sternal wound infection $(0.6 \%) .{ }^{6}$ Most patients requiring reoperative AVR were rightfully considered high risk, and after the approval of transcatheter aortic valve replacement (TAVR) for native aortic stenosis, many clinicians looked to failing bioprosthetic valves as the next area in which to expand TAVR indications.

The aortic VIV procedure is TAVR for the treatment of failing bioprosthetic valves, which has become a reasonable alternative to reoperative AVR. The procedure takes advantage of the stent frame of the failing bioprosthesis by anchoring into a uniformly rigid structure that is often visible on fluoroscopy (Figure 1, C and D). Currently, both balloon-expandable and self-expanding transcatheter heart valves (THVs) are commercially approved for

From the Division of Cardiac Surgery, Department of Surgery, Bluhm Cardiovascular Institute, Northwestern Medicine and Northwestern University Feinberg School of Medicine, Chicago, Ill

Received for publication Oct 13, 2020; revisions received Dec 11, 2020; accepted for publication Dec 22, 2020; available ahead of print Feb 4, 2021.

Address for reprints: S. Chris Malaisrie, MD, Division of Cardiac Surgery, Northwestern University Feinberg School of Medicine, Northwestern Medicine, $676 \mathrm{~N}$ St. Clair, Suite 7-324, Chicago, IL 60611 (E-mail: chris.malaisrie@nm.org). J Thorac Cardiovasc Surg 2022;163:1795-8 $0022-5223 / \$ 36.00$

Copyright (C) 2021 by The American Association for Thoracic Surgery https://doi.org/10.1016/j.jtcvs.2020.12.148 


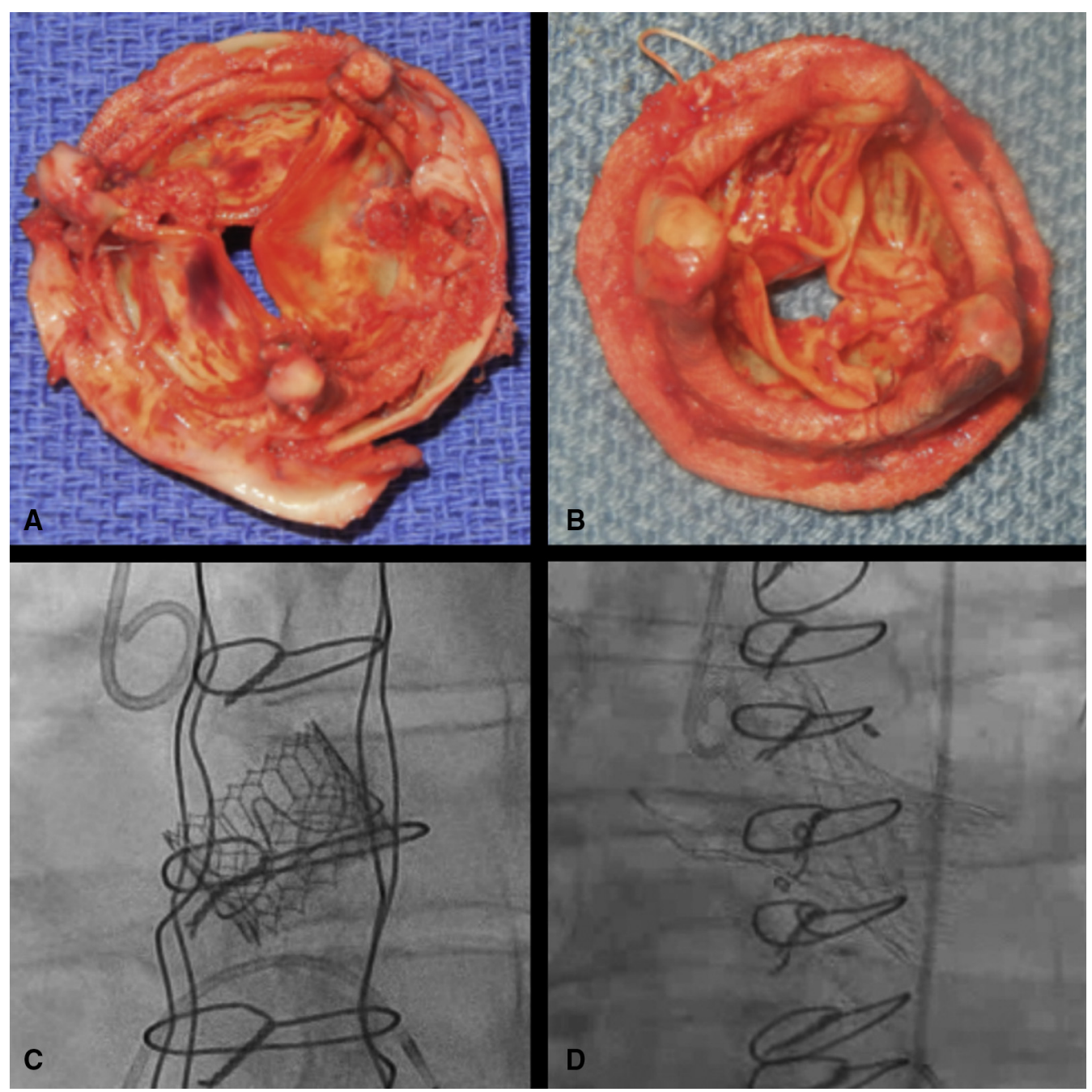

FIGURE 1. Bovine (A) and porcine (B) valves treated with balloon-expandable (C) or self-expanding (D) valves.

Although most comparative effectiveness studies have shown similar early mortality between groups, ${ }^{13-15}$ some studies have found that 30-day and long-term survival significantly favor aortic VIV. A multicenter Canadianbased propensity-matched trial showed both lower early mortality (absolute risk reduction ARD, $-7.5 \% ; 95 \%$ confidence interval $[\mathrm{CI}],-12.6 \%$ to $-2.3 \%$ ) and increased late survival $(77 \%$ vs $67 \% ; P=.046) .{ }^{16}$ A recent French study retrospectively reviewed a matched, even distribution of 1428 patients undergoing aortic VIV or reoperative AVR and showed a lower 30-day mortality in the former group (odds ratio [OR], 0.48; 95\% CI, 0.30-0.78). ${ }^{17}$ Finally, a recent review of the US National Readmission Database showed a significantly lower 30-day mortality in the aortic VIV group (OR, 0.41; 95\% CI, 0.23-0.74). ${ }^{18}$ Based on these data, early mortality associated with aortic VIV is at least as good as, if not better than, that for reoperative AVR.

Not surprisingly, these same studies have shown lower perioperative morbidity after aortic VIV compared with reoperative AVR. Comparative data from the Mayo Clinic clearly demonstrated a reduced rate of major complications after aortic VIV, including a significantly lower risk of procedure-related complications $(23 \%$ vs $59 \%$; $P<.001)$, prolonged ventilation ( $3 \%$ vs $15 \% ; P=.002)$, renal failure ( $4 \%$ vs $19 \% ; P<.001)$, and blood transfusions $(12 \%$ vs $53 \% ; P<.001)$ compared with reoperative AVR. ${ }^{14}$ Another large, propensity-matched analysis showed a significantly lower risk of morbidity in the aortic VIV group (OR, 0.56; 95\% CI, 0.43-0.72). ${ }^{18}$ Finally, in several studies the median length of stay in the aortic VIV group was approximately half that in the reoperative AVR group, and the median ICU length of stay was significantly shorter in the former group ( 0 vs 68 hours; $P=.001$ ). ${ }^{13,16,19}$

Rhythm disturbances including heart block requiring permanent pacemaker and new-onset atrial fibrillation appear to be less frequent after aortic VIV than after reoperative AVR. Conceptually, the risk of heart block after aortic VIV should not be significantly elevated, because the THV is anchored within the surgical bioprosthesis and not the native aortic annulus. Notably, the rate of pacemaker 
implantation after aortic VIV is indeed lower as compared with TAVR for native AS $(3 \%$ vs $10.9 \% ; P<.001) .{ }^{10}$ However, comparative data regarding heart block following aortic VIV versus reoperative AVR is less definitive, but also suggests a significantly lower rate of permanent pacemaker (absolute risk reduction, $-9.8 \% ; 95 \% \mathrm{CI},-16.1 \%$ to $-3.4 \%$ ) following aortic VIV. ${ }^{16}$ It is already well known that new-onset atrial fibrillation occurs less frequently after TAVR than SAVR for native AS. A recent multicenter study showed a similar effect after aortic VIV with a lower risk of new-onset atrial fibrillation following aortic VIV $(0.6 \%$ vs $4.0 \%$; OR, 0.13; 95\% CI, 0.05-0.38). ${ }^{17}$ Taken as a whole, aortic VIV demonstrates improving safety in terms of both 30-day mortality, major morbidity and rhythm disturbance when compared with reoperative AVR.

A special subset of patients are those with failing aortic homografts or stentless bioprosthesis. Homograft failure typically results in aortic regurgitation and the implant technique for aortic VIV is not established, owing to the variability of the proximal suture line of the homograft. ${ }^{20}$ On the other hand, reoperation for failed homograft is more challenging than for failed AVR owing to homograft calcification, which is often severe. Comparative studies have paralleled those for aortic VIV for stented bioprosthesis in terms of early mortality and perioperative complications, ${ }^{21}$ but some centers including ours have shown that late valve migration may be a concern. ${ }^{20}$ Thus, although aortic VIV for failed aortic homografts is feasible, long-term outcomes deserve attention.

\section{LIMITATIONS OF TAVR APPROACH}

Coronary obstruction is a limitation of aortic VIV and occurs when the frame of the THV pushes the leaflets of the old bioprosthetic valve into a cylindrical configuration. ${ }^{22}$ Risk factors include sinus effacement (so-called "stovepipe" root) and the design of bioprosthetic valves (internally vs externally wrapped design). Coronary obstruction is typically treated with emergency coronary stenting and less frequently with emergency coronary artery bypass grafting with or without mechanical circulatory support. ${ }^{23}$ Appropriate patient selection using advanced imaging has reduced the risk of coronary obstruction which is now $<1 \%{ }^{24}$

A solution for those patients at risk for coronary obstruction is the bioprosthetic or native aortic scallop intentional laceration to prevent iatrogenic coronary artery obstruction (BASILICA) procedure. ${ }^{25}$ The BASILICA procedure is performed at the same setting as aortic VIV but just before valve implantation. In this procedure, the leaflet of the surgical bioprosthesis is lacerated with an energized wire to expose the coronary artery os and can be repeated for both coronary leaflets. The reported outcomes after BASILICA show effectiveness of the procedure $(93 \%)$, but at the cost of increased stroke $(10 \%) .{ }^{25}$ Of note, unplanned intervention and procedural mortality after BASILICA were both zero and only a single mortality $(3 \%)$ was recorded at
30 days. $^{25}$ Thus, current data has established reasonable safety of the BASILICA with aortic VIV, especially in patients who are not candidates for reoperative AVR.

The stent of the bioprosthetic valve affords a reliable landing zone for the THV but at the same time is another limitation of the aortic VIV procedure. The implanted THV can expand no larger than the stent of the failing bioprosthetic valve, a problem not relevant to reoperative AVR, where the failing bioprosthesis is removed. The implantation of a smaller valve can result in patient-prosthesis mismatch (PPM). The mean gradient after aortic VIV has been reported to be $17-18 \mathrm{mmHg}$ for both balloon-expandable and self-expanding THV. ${ }^{11,12}$ Smaller bioprosthetic valves are at increased risk for PPM after aortic VIV compared with larger valve sizes. Furthermore, PPM is associated with reduced survival, increased readmission rates, and late structural valve deterioration. ${ }^{26,27}$ Although patient selection can reduce the risk of PPM after aortic VIV, many patients after aortic VIV will be exposed to elevated gradients, which may affect long-term outcome. ${ }^{28}$

During aortic VIV, the risk of PPM can be mitigated by fracturing the stent of the bioprosthetic valve. The valve fracture (VF) technique is performed by inflating a highpressure balloon (sometimes $>20$ ATM) within the frame of the surgical bioprosthesis either before or after THV implantation and can increase valve diameter by up to $4 \mathrm{~mm} .{ }^{29}$ Although not recommended by THV manufacturers, the procedure has been associated with a decrease in valve gradients of $10.9 \mathrm{mmHg}$ and increase in effective valve area by $0.7 \mathrm{~cm}^{2}$ with acceptable procedural safety (30-day mortality, $2.7 \%) .{ }^{30}$ The concept of bioprosthetic valve stent expansion is also currently featured in a commercially available surgical bioprosthetic valve. ${ }^{31}$ Overall, elevated gradients and PPM continues to be a limitation of aortic VIV, but VF with high-pressure balloon is an attractive solution especially in bioprosthetic valves amenable to stent fracture.

The durability of THV used during aortic VIV remains unknown. Patients at high risk for reoperative AVR may never see the long-term benefit of valve durability due to poor overall survival (estimated to be $66 \%$ at 5 years), making aortic VIV a reasonable alternative to reoperative AVR in this cohort of patients. ${ }^{5,8,9}$ The durability of THV is more pertinent to lower risk and younger patients and this important endpoint will be followed out to 10 years in the lowrisk, randomized trials for native $\mathrm{AS}^{32,33}$ In addition, a currently enrolled trial for low-risk and intermediate-risk patients undergoing aortic VIV has planned 10-year follow-up and the investigators will report 1-year outcomes in early 2021 (ClinicalTrials.gov identifier NCT 03003299).

\section{CONCLUSIONS}

The debate between aortic VIV and reoperative AVR is framed by the trade-off between safety and durability. A 
transcatheter approach using aortic VIV has demonstrated low 30-day mortality and considerably lower perioperative morbidity compared with reoperative AVR. ${ }^{14,16}$ The majority of patients with failing bioprosthetic valves are older and THV durability might not be a compelling issue. ${ }^{14}$ Further investigation in younger patients is necessary before expanding indications for aortic VIV, but more therapeutic options are needed for the growing number of patients who are currently receiving bioprosthetic valves and face the challenge of BVF in the future.

\section{Conflict of Interest Statement}

Dr Malaisrie has received honoraria from Edwards Lifesciences, Medtronic, Cryolife, and Abbott. Dr Clark has reported no conflicts of interest.

The Journal policy requires editors and reviewers to disclose conflicts of interest and to decline handling or reviewing manuscripts for which they may have a conflict of interest. The editors and reviewers of this article have no conflicts of interest.

\section{References}

1. Dvir D, Bourguignon T, Otto CM, Hahn RT, Rosenhek R, Webb JG, et al. Standardized definition of structural valve degeneration for surgical and transcatheter bioprosthetic aortic valves. Circulation. 2018;137:388-99.

2. Kappetein AP, Head SJ, Généreux P, Piazza N, van Mieghem NM, Blackstone EH, et al. Updated standardized endpoint definitions for transcatheter aortic valve implantation: the Valve Academic Research Consortium-2 consensus document. J Am Coll Cardiol. 2012;60:1438-54.

3. Kaneko T, Loberman D, Gosev I, Rassam F, McGurk S, Leacche M, et al. Reoperative aortic valve replacement in the octogenarians - minimally invasive technique in the era of transcatheter valve replacement. J Thorac Cardiovasc Surg. 2014;147:155-62.

4. LaPar DJ, Yang Z, Stukenborg GJ, Peeler BB, Kern JA, Kron IL, et al. Outcomes of reoperative aortic valve replacement after previous sternotomy. J Thorac Cardiovasc Surg. 2010;139:263-72.

5. Leontyev S, Borger MA, Davierwala P, Walther T, Lehmann S, Kempfert J, et al. Redo aortic valve surgery: early and late outcomes. Ann Thorac Surg. 2011;91:1120-6.

6. Potter DD, Sundt TM III, Zehr KJ, Dearani JA, Daly RC, Mullany CJ, et al. Operative risk of reoperative aortic valve replacement. J Thorac Cardiovasc Surg. 2005; 129:94-103.

7. Webb JG, Dvir D. Transcatheter aortic valve replacement for bioprosthetic aortic valve failure: the valve-in-valve procedure. Circulation. 2013;127:2542-50.

8. Nishimura RA, Otto CM, Bonow RO, Carabello BA, Erwin JP III, Fleisher LA, et al. 2017 AHA/ACC focused update of the 2014 AHA/ACC Guideline for the management of patients with valvular heart disease: a report of the American College of Cardiology/American Heart Association task force on clinical practice guidelines. J Am Coll Cardiol. 2017;70:252-89.

9. Baumgartner H, Falk V, Bax JJ, De Bonis M, Hamm C, Holm PJ, et al. 2017 ESC/ EACTS guidelines for the management of valvular heart disease. Eur Heart J. 2017;38:2739-91.

10. Tuzcu EM, Kapadia SR, Vemulapalli S, Carroll JD, Holmes DR Jr, Mack MJ, et al. Transcatheter aortic valve replacement of failed surgically implanted bioprostheses: the STS/ACC Registry. J Am Coll Cardiol. 2018;72:370-82.

11. Webb JG, Mack MJ, White JM, Dvir D, Blanke P, Herrmann HC, et al. Transcatheter aortic valve implantation within degenerated aortic surgical bioprostheses: PARTNER 2 Valve-in-Valve Registry. J Am Coll Cardiol. 2017;69:2253-62.

12. Deeb GM, Chetcuti SJ, Reardon MJ, Patel HJ, Grossman PM, Schreiber T, et al. One-year results in patients undergoing transcatheter aortic valve replacement with failed surgical bioprostheses. JACC Cardiovasc Interv. 2017;10:1034-44.

13. Ejiofor JI, Yammine M, Harloff MT, McGurk S, Muehlschlegel JD, Shekar PS, et al. Reoperative surgical aortic valve replacement versus transcatheter valve-invalve replacement for degenerated bioprosthetic aortic valves. Ann Thorac Surg. 2016;102:1452-8.
14. Sedeek AF, Greason KL, Sandhu GS, Dearani JA, Holmes DR Jr, Schaff HV. Transcatheter valve-in-valve vs surgical replacement of failing stented aortic biological valves. Ann Thorac Surg. 2019;108:424-30.

15. Raschpichler MC, Woitek F, Chakravarty T, Flint N, Yoon SH, Mangner N, et al. Valve-in-valve for degenerated transcatheter aortic valve replacement versus valve-in-valve for degenerated surgical aortic bioprostheses: a 3-center comparison of hemodynamic and 1-year outcome. J Am Heart Assoc. 2020;9:e013973.

16. Tam DY, Dharma C, Rocha RV, Ouzounian M, Wijeysundera HC, Austin PC, et al. Transcatheter ViV versus redo surgical AVR for the management of failed biological prosthesis: early and late outcomes in a propensity-matched cohort. JACC Cardiovasc Interv. 2020;13:765-74.

17. Deharo P, Bisson A, Herbert J, Lacour T, Saint Etienne C, Porto A, et al. Transcatheter valve-in-valve aortic valve replacement as an alternative to surgical rereplacement. J Am Coll Cardiol. 2020;76:489-99.

18. Hirji SA, Percy ED, Zogg CK, Malarczyk A, Harloff MT, Yazdchi F, et al. Comparison of in-hospital outcomes and readmissions for valve-in-valve transcatheter aortic valve replacement vs reoperative surgical aortic valve replacement: a contemporary assessment of real-world outcomes. Eur Heart J. 2020;41:2747-55.

19. Patel PM, Chiou E, Cao Y, Binogo J, Guyton RA, Leshnower B, et al. Isolated redo-aortic valve replacement versus valve-in-valve transcatheter valve replacement. Ann Thorac Surg. October 28, 2020 [Epub ahead of print].

20. Kislitsina ON, Szlapka M, McCarthy PM, Davidson CJ, Flaherty JD, Sweis RN, et al. Unique technical challenges in patients undergoing TAVR for failed aortic homografts. J Card Surg. 2021;36:89-96.

21. Sedeek AF, Greason KL, Nkomo VT, Eleid MF, Maltais S, Williamson EE, et al. Repeat aortic valve replacement for failing aortic root homograft. J Thorac Cardiovasc Surg. 2019;158:378-85.e2.

22. Dvir D, Webb J, Brecker S, Bleiziffer S, Hildick-Smith D, Colombo A, et al. Transcatheter aortic valve replacement for degenerative bioprosthetic surgical valves: results from the global valve-in-valve registry. Circulation. 2012;126:2335-44.

23. Ribeiro HB, Rodés-Cabau J, Blanke P, Leipsic J, Kwan Park J, Bapat V, et al. Incidence, predictors, and clinical outcomes of coronary obstruction following transcatheter aortic valve replacement for degenerative bioprosthetic surgical valves: insights from the VIVID registry. Eur Heart J. 2018;39:687-95.

24. Dvir D, Leipsic J, Blanke P, Ribeiro HB, Kornowski R, Pichard A, et al. Coronary obstruction in transcatheter aortic valve-in-valve implantation: preprocedural evaluation, device selection, protection, and treatment. Circ Cardiovasc Interv. 2015;8:e002079.

25. Khan JM, Greenbaum AB, Babaliaros VC, Rogers T, Eng MH, Paone G, et al. The BASILICA trial: prospective multicenter investigation of intentional leaflet laceration to prevent TAVR coronary obstruction. JACC Cardiovasc Interv. 2019; $12: 1240-52$.

26. Fallon JM, DeSimone JP, Brennan JM, O'Brien S, Thibault DP, DiScipio AW, et al. The incidence and consequence of prosthesis-patient mismatch after surgical aortic valve replacement. Ann Thorac Surg. 2018;106:14-22.

27. Flameng W, Herregods MC, Vercalsteren M, Herijgers P, Bogaerts K, Meuris B Prosthesis-patient mismatch predicts structural valve degeneration in bioprosthetic heart valves. Circulation. 2010;121:2123-9.

28. Webb JG, Murdoch DJ, Alu MC, Cheung A, Crowley A, Dvir D, et al. 3-Year outcomes after valve-in-valve transcatheter aortic valve replacement for degenerated bioprostheses: the PARTNER 2 Registry. J Am Coll Cardiol. 2019;73:2647-55.

29. Allen KB, Chhatriwalla AK, Cohen DJ, Saxon JT, Aggarwal S, Hart A, et al. Bioprosthetic valve fracture to facilitate transcatheter valve-in-valve implantation. Ann Thorac Surg. 2017;104:1501-8.

30. Allen KB, Chhatriwalla AK, Saxon JT, Cohen DJ, Nguyen TC, Webb J, et al. Bioprosthetic valve fracture: technical insights from a multicenter study. J Thorac Cardiovasc Surg. 2019;158:1317-28.e1.

31. Puskas JD, Bavaria JE, Svensson LG, Blackstone EH, Griffith B, Gammie JS, et al. The COMMENCE trial: 2-year outcomes with an aortic bioprosthesis with RESILIA tissue. Eur J Cardiothorac Surg. 2017;52:432-9.

32. Mack MJ, Leon MB, Thourani VH, Makkar R, Kodali SK, Russo M, et al. Transcatheter aortic-valve replacement with a balloon-expandable valve in low-risk patients. N Engl J Med. 2019;380:1695-705.

33. Popma JJ, Deeb GM, Yakubov SJ, Mumtaz M, Gada H, O'Hair D, et al. Transcatheter aortic-valve replacement with a self-expanding valve in low-risk patients. N Engl J Med. 2019;380:1706-15.

Key Words: structural valve deterioration, transcatheter aortic valve replacement, valve-in-valve procedure, reoperation aortic valve replacement 